\title{
Activation of the human immunodeficiency virus type I long terminal repeat by $1 \alpha, 25$-dihydroxyvitamin D3
}

\author{
Julián Nevado ${ }^{1}$, Stephan P Tenbaum ${ }^{2}$, Ana Isabel Castillo, Aurora Sánchez-Pacheco \\ and Ana Aranda
}

\begin{abstract}
Instituto de Investigaciones Biomédicas (CSIC)-Universidad Autónoma de Madrid, Arturo Duperier 4, 28029 Madrid, Spain, ${ }^{1}$ Unidad de Investigación, Hospital Universitario de Getafe, Getafe, 28905 Madrid, Spain and ${ }^{2}$ Centro Nacional de Investigaciones Oncológicas (CNIO), 28029 Madrid, Spain
\end{abstract}

(Requests for offprints should be addressed to A Aranda; Email: aaranda @iib.uam.es)

\begin{abstract}
The genetic predisposition of the host and the virus is the most important determinant for prediction of the course of human immunodeficiency virus type I (HIV-1) viral infection and acquired immune deficiency syndrome (AIDS) progression. Transcription from the HIV-1 long terminal repeat (LTR) is a crucial step for viral replication. Here, we describe a stimulatory role of the vitamin $\mathrm{D}$ receptor (VDR) on HIV-1 LTR transactivation. Transient transfections reveal that VDR activates the LTR in HeLa, U937, and Cos-1 cells in a ligand-dependent manner. 1 $\alpha, 25-$ Dihydroxyvitamin D3 (vitD3) promotes activation of a minimal LTR construct (from nucleotides -35 to +89 ), lacking a previously described hormone response element that binds several nuclear receptors. NF- $\kappa B$ (nuclear factor-kappa B) and Sp1-binding sites, which are responsible for most basal LTR activity in HeLa cells, are also dispensable for vitD3-dependent HIV-1 transcription. Although the tat response element element is not required for VDR-mediated HIV-1 gene expression, the viral protein Tat acts in a synergistic manner with the receptor to stimulate LTR activity. Furthermore, our data also show cooperation of the receptor with various cellular coactivators for HIV-1 transactivation by vitD3. Paradoxically, mutations in the VDR ligand-dependent transcriptional activation function-2 that abrogate vitD3-dependent stimulation through classical vitamin D response elements, do not reduce vitD3-mediated LTR transactivation. Furthermore, point mutations in the DNA-binding domain that abolish receptor binding to consensus DNA sequences do not affect ligand-dependent HIV-1 stimulation. These results show that VDR activates the HIV-1 LTR through different mechanisms, including nonclassical nuclear receptor transcriptional actions that may ensure viral transcription under different physiological scenarios.
\end{abstract}

Journal of Molecular Endocrinology (2007) 38, 587-601

\section{Introduction}

Human immunodeficiency virus type I (HIV-1) is responsible for the development of AIDS. It has been suggested that viral replication may involve complex interactions among chromatin-associated pro-viral DNA, cellular transcription factors, and viral proteins (VPs; El Kharroubi et al. 1998). The transcription of the viral genome is directed by the long terminal repeat (LTR) sequences. Numerous studies have identified essential DNA elements within the LTR, located between nucleotides -454 and +184 , as well as many host and VPs for the transcriptional activation of the LTR in vitro, and in cultured cells (Pereira et al. 2000, Rohr et al. 2003). The involvement of multiple host factors in HIV-1 transcription suggests that HIV-1 propagation and AIDS progression are likely to be influenced by physiological conditions that affect the availability and function of host factors. So far, the genetic predisposition of the host and the virus is the most important determinant for prediction and understanding the course of HIV infection and progression to AIDS. At this respect, previous studies have revealed that ligands of nuclear receptors such as thyroid hormones (T3) may have a role in AIDS development (LoPresti et al. 1989). In fact, data from our laboratory, among others, have demonstrated a role for T3 and retinoic acid (RA), other nuclear receptor ligands, on HIV-1 LTR regulation, demonstrating the binding of RA receptors (RARs) and T3 receptors (TRs) to different LTR regions (Desai-Yajnik \& Samuels 1993, Sawaya et al. 1996, Xu et al. 1996, Recio et al. 2000, Hsia \& Shi 2002). A very recent study has also shown stimulation of HIV-1 transactivation by $17 \beta$-estradiol via the nuclear estrogen receptor (ER)- $\alpha$, augmenting Sp-1 DNA binding and transcriptional activity (Katagiri et al. 2006).

Interestingly, other studies had shown that several variations at the locus coding for the vitamin $\mathrm{D}$ receptor (VDR) are associated with susceptibility and progression of several immune diseases, including AIDS (Barber et al. 2001, Nieto et al. 2004). VDRs are members of the superfamily of nuclear receptors, which act as ligand-inducible transcription factors by 
binding generally as heterodimers with the retinoid $\mathrm{X}$ receptor (RXR) to hormone responsive elements (HRE), normally located in the regulatory regions of their target genes (Mangelsdorf et al. 1995). In the case of VDR, the most common response elements (VDREs) are composed of direct repeats of the sequence AGG/ TTCA spaced by three nucleotides (DR3). The receptors bind the HREs through a DNA-binding domain (DBD) or region $\mathrm{C}$, which contains two zinc fingers. Upon ligand binding, the receptors undergo conformational changes that facilitate recruitment of coactivators responsible for gene activation (for review see Aranda \& Pascual 2001).

In the present study, we aimed to investigate the control of the HIV-1 LTR activity by VDR in HeLa cells, and eventually to unmask the elements involved in this regulation. The data obtained strongly support the view that VDR and its ligand may play a role in HIV-1 transactivation through several classical and nonclassical nuclear receptor transactivation mechanisms.

\section{Materials and methods}

\section{Plasmids}

Different reporter plasmids used in this study have been previously described elsewhere: -453 HIV-luc contains HIV-1 LTR sequences from -452 to +80 bp fused to luciferase, and in $-453 \Delta \mathrm{NF}-\kappa \mathrm{BHIV}-\mathrm{luc}$ the GCG motif of both NF- $\kappa \mathrm{B}$ sites located at $-104 /-76$ was mutated to TCT (Devary et al. 1993). Deletion mutants extending from -453 to nucleotides $-104,-76$, and -28 of the HIV-1 LTR, and $-453 \Delta$ HREHIV-luc in which a nuclear receptor-binding site is mutated, have been previously described (Recio \& Aranda 1997, Recio et al. 2000). HIV LTR Tat response element ( $\Delta$ TAR)luc (pXp1LTR $\triangle T A R)$ has been described in (GomezGonzalo et al. 2001). The $4 \times$ VDRE-TK-Luc reporter plasmid bears four copies of DR3 type VDRE from the rat $A N F$ gene promoter (Herdick et al. 2000). The expression vector for Tat (1-86; LRG286), a gift from Dr Gaudreau, has been cloned in pcIneo plasmid containing the cytomegalovirus promoter (CMV). Expression vectors for steroid receptor coactivator-1 (SRC-1; Henttu et al. 1997), CBP/p300 (Chakrabarti et al. 1996), and DRIP205 (Rachez et al. 1999), were previously described. Glutathione $S$-transferase (GST)SRC-1 contains the receptor interacting domain from residues 570 to 780 . Human VDR and $\operatorname{RXR} \alpha$, its truncated activation function (AF)-2 and VDR $\Delta 1-111$ forms, and the VDR-mutants K246A, E417A, and E420Q have been also described (Jiménez-Lara \& Aranda $1999 a, b)$.

To construct the DBD VDR mutants C24G, K45E, and C24G/K45E, site directed mutagenesis was performed by PCR with Pfu Turbo DNA polymerase (Stratagene) using hVDR (pSG5) or GST-VDR (pGEx) plasmid as templates, and the following oligonucleotides: sense, 5'-GTGCCCCGGATCGGCGGGGTGTGTGGA-3' ${ }^{\prime}$ (for C24G), 5'-TGTGAAGGCTGCGAAGGCTCTTTCAGG$3^{\prime}$ (for K45E), containing the desired nucleotides changes, as well as the corresponding antisense oligonucleotides. The $5^{\prime}$-TGTGAAGGCTGCGAAGGCTCTTTCAGG-3' ${ }^{\prime}$ oligonucleotide was used for constructing $\mathrm{C} 24 \mathrm{G} / \mathrm{K} 45 \mathrm{E}$ using $\mathrm{C} 24 \mathrm{G}$ mutant as a template. Mutations were confirmed by direct DNA sequencing.

\section{Cell cultures and transfections}

HeLa and Cos-1 cells were obtained from the American Type Cell Culture (ATCC) and are maintained in DMEM containing $10 \%$ fetal calf serum. U-937 cells were kindly provided by Dr S Alemany. For transfection experiments, cells were plated in six-well dishes at a density of $1-2 \times 10^{6}$ cells/well. Transfections were performed with $1.5 \mu \mathrm{l} / \mu \mathrm{g}$ DNA mixture of commercial liposomes which is composed of DDAB (SIGMA D2779) and DOPE (SIGMA P1223) at a 1:1 ratio. In all experiments, the amount of DNA was kept constant by addition of the required amount of 'empty' vectors. Mixtures were incubated for $20-30 \mathrm{~min}$ at room temperature, added to the six-well plates and incubation was continued for other $12 \mathrm{~h}$. Cells were washed again and maintained in DMEM serum-free medium before treatment with vitD3, or its analogs. After $24 \mathrm{~h}$, cells were harvested and lysed by freezing and thawing once in $1 \times$ Reporter Lysis Buffer (Promega). The obtained extracts were then centrifuged for $20 \mathrm{~s}$ at $12000 \mathrm{~g}$, and used to assay luciferase activity following the manufacturer's specifications (Promega). Luciferase activity was corrected by the amount of protein of the different extracts. Triplicates of each condition were considered for analysis, and in all cases each experiment was repeated at least three times. Data presented are the mean \pm s.D. values obtained.

\section{GST-pull-down experiments}

To assay protein-protein interactions in vitro, recombinant GST-fusion proteins were expressed in the bacterial strain BL21 (DE3), and purified using standard techniques. Pull-down assays were performed with $5 \mu \mathrm{l}$ in vitro translated $\left[{ }^{35} \mathrm{~S}\right]$ methionine-labeled VDR or the same amounts of its truncated forms (TNTT7, Quick Transcription/Translation System, Promega) in GST-interaction buffer (25 mM HEPES, pH 7.9; $50 \mathrm{mM} \mathrm{KCl} ; 6 \%$ glycerol; $5 \mathrm{mM} \mathrm{MgCl}_{2} ; 1 \mathrm{mM}$ dithiothreitol; $0.05 \%$ Triton X-100; $1 \mathrm{mM}$ phenylmethylsulphonyl fluoride; $5 \mathrm{mM}$ EDTA). These proteins were 
incubated with the fusion protein GST-SRC-1 or with the same amount of GST alone, immobilized in glutathione-sepharose beads (Amersham, Pharmacia Biotech) as previously described (Jiménez-Lara \& Aranda $1999 a$ ). When indicated, $1 \mu \mathrm{M}$ vitD3 was included in the binding reaction. The bound proteins were analyzed by SDS-PAGE and autoradiography.

\section{Gel mobility shift assays}

Electrophoretic mobility shift assays with a consensus VDRE were performed using $2.5 \mu \mathrm{l}$ each of in vitro translated RXR and VDR or its mutants in the presence and absence of recombinant SRC-1 as previously described (Jiménez-Lara \& Aranda 1999b). The VDRE oligonucleotide used was 5'-AGCTCAGGTCAAGGAGGTCAG-3'. Gel retardation assays were also performed with the oligonucleotide 5 '-A TAT AAG CAG CTG CTT TTT GCC TGT ACT GGG TCT CTC TGG TTA GAC CAG ATC TGA GCC-3' ${ }^{\prime}$, containing sequences from -28

HeLa cells

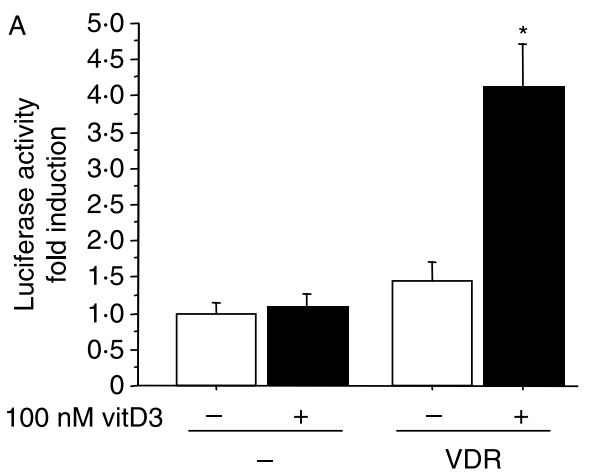

HeLa cells

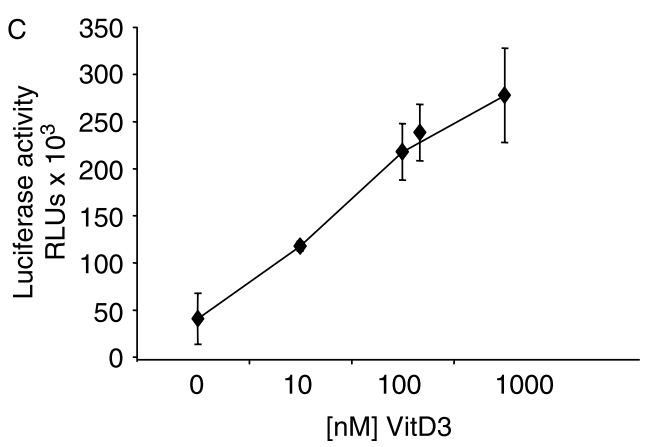

to +30 of the HIV-1 LTR and $100 \mathrm{ng}$ recombinant RXR and/or VDR or its mutants. When indicated vitD3 $(1 \mu \mathrm{M})$ was included in the binding reactions.

\section{Statistics analysis}

The statistical analysis was carried out using the Stat-View statistics program (Abacus Concepts, Inc., Berkeley, CA, USA). Differences in the mean or in the variance were evaluated using the factorial ANOVA, followed by Fisher's protected least significance test with the level of significance chosen at $P \leq 0 \cdot 05$.

\section{Results}

\section{VDR is able to transactivate the HIV-1 LTR in the presence of vitD3}

Figure 1A shows transactivation of the HIV-1 LTR $(-453 \mathrm{HIV}-\mathrm{luc})$ in the presence and absence of VDR
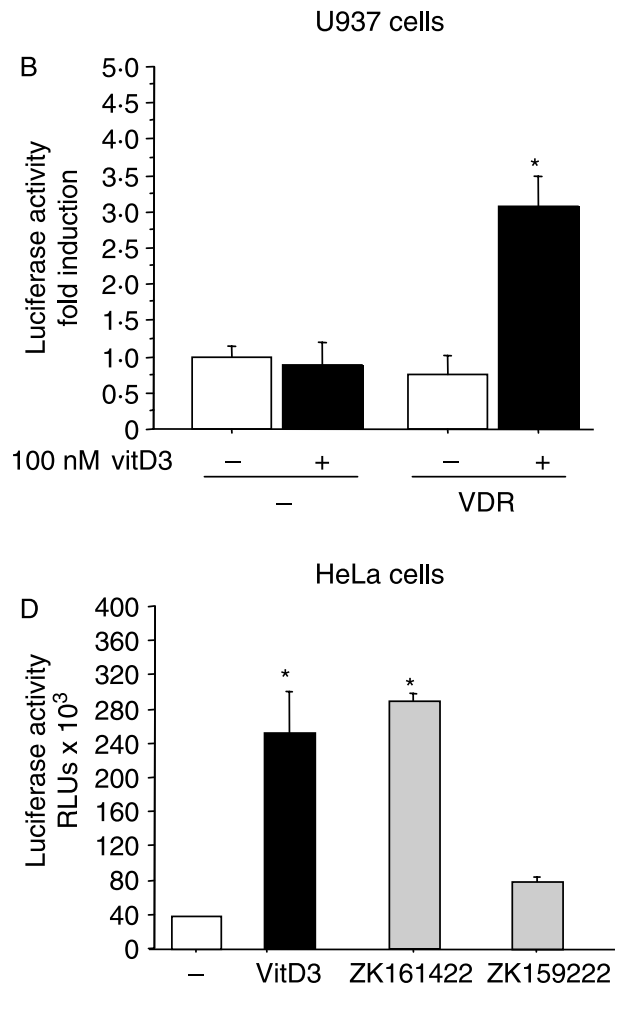

Figure 1 Vitamin D3 stimulates HIV-1 LTR transcription. HeLa cells (A, C, and D) and U937 cells (B) were transfected with the reporter plasmid $-453 \mathrm{HIV}$-LUC, which contains HIV-1 LTR sequences from -453 to +80 fused to the luciferase gene. (A and B) VDR-mediated HIV promoter activity in response to $100 \mathrm{nM}$ vitamin D3 (vitD3) for $48 \mathrm{~h}$. (C) HIV promoter activity in response to treatment with increasing concentrations of vitD3 for $48 \mathrm{~h}$. (D). HIV promoter activity in cells treated for $48 \mathrm{~h}$ with a $100 \mathrm{nM}$ concentration of vitD3 or the vitamin D analogs ZK161422 and ZK15922. Data of luciferase activity were expressed as either fold induction over the values obtained in $\mathrm{Et}-\mathrm{OH}$-treated control cells in the absence of VDR ( $\mathrm{A}$ and $\mathrm{B}$ ) or RLUs (C and $\mathrm{D})$. * $P \leq 0.05$ versus EtOH-treated cells. 
and its ligand in HeLa cells. Incubation of VDRexpressing cells with $100 \mathrm{nM}$ vitD3 was able to induce HIV-1 LTR transcription about fourfold $(P \leq 0 \cdot 05)$, while almost no induction was observed in the absence of ligand $(1 \cdot 50 \pm 0 \cdot 25$-fold induction over non-VDRtransfected cells; Fig. 1A). In order to distinguish whether VDR-mediated LTR transactivation was a celltype specific effect, we further analyzed this effect in human U937 cells, which are putative hematopoietic target cells of the HIV virus in vivo. Stimulation by vitD3 was similar in range to that observed in HeLa cells (about $4 \cdot 5$-fold, Fig. 1B). Closely similar results were obtained in transiently transfected Cos-1 cells (data not shown). All these data together indicate that liganded VDR is able to induce transcription from the HIV-1 LTR in different cell types.

Further transient transfection experiments of HeLa cells with the 453HIV-luc reporter in presence of increasing concentrations of vitD3 (0-1000 nM) showed that the vitamin stimulated the HIV-1 LTR in a dose-dependent manner, with a half-maximal luciferase induction obtained with approximately $75 \mathrm{nM}$ vitD3 (Fig. 1C). In addition, the synthetic vitamin D agonist ZK161422 at $100 \mathrm{nM}$ was as potent as vitD3 (Fig. 1D), and is also a good putative candidate to activate the HIV-1 LTR. In contrast, the same concentration of the vitD3 analog ZK159222 that binds VDR with high affinity but shows a partial vitD3 antagonistic activity, barely increased HIV-1 LTR transactivation (Fig. 1D).

\section{Transactivation of HIV-1 LTR truncated forms by vitD3}

A series of $5^{\prime}$ deletion constructs derived from -453 HIV-luc, as well as several mutated constructs, were used to define the elements responsible for basal and VDRstimulated HIV-1 LTR expression in HeLa cells (Fig. 2). A mutant of $-453 \mathrm{HIV}$-luc ( $-453 \Delta \mathrm{HRE})$, affecting a previously described HRE that binds multiple nuclear receptors, including VDR (Ladias 1994), showed a slightly decreased basal activity versus the wild-type promoter, but interestingly stimulation by vitD3 $(100 \mathrm{nM})$ was at least as high as that produced on the wild-type promoter $(3 \cdot 96 \pm 0 \cdot 56$-fold induction over control cells). In addition, removal of the LTR sequences from -453 to $-104 \mathrm{bp}$, which deletes among others the HRE, increased the basal activity of this LTR construct (around 1.5-1.7-fold over basal), and still showed a significant response to the hormone as compared with the -453 HIV-luc reporter plasmid $(4 \cdot 10 \pm 0 \cdot 70$-fold induction). These results suggest that elements different from the HRE contribute to VDRmediated HIV-1 LTR activation in HeLa cells.

The core HIV-1 LTR promoter also contains two NF$\kappa \mathrm{B}$-binding sites (at nucleotides -104 to -81 ), and Fig. 2 shows that mutations of these motifs reduced very significantly basal luciferase levels (up to 2-3-fold), as well as vitD3-mediated activation (from $3 \cdot 20 \pm 0 \cdot 17$ - to $2 \cdot 10 \pm 0 \cdot 16$-fold induction). However, the induction by vitD3 observed in the absence of these motifs was still statistically significant. Accordingly, a shorter LTRbased construct extending to $-76 \mathrm{bp}$, in which both NF-кB-binding sites were deleted, showed a pattern of basal and vitD3-induced activation that was similar to that observed with the mutant construct. These results confirm that these elements have an important role for basal HIV-1 LTR activity in these cells, and suggest that although NF-kB-binding sites may play a minor role HIV-1 LTR transactivation by VDR, additional elements must participate in this stimulation.

Related to that, and in close proximity to the NF- $\kappa \mathrm{B}$ sites, the HIV-1 LTR also contains three binding sites for the transcription factor Sp1 (from nucleotide -76 to $-46)$. Indeed, a cooperative interaction between both transcription factors, NF- $\mathrm{B}$ and $\mathrm{Sp} 1$, has been shown to be required for viral activation (Perkins et al. 1993). Thus, we also analyzed the deletion of the LTR to $-28 \mathrm{bp}$, which eliminates the three Sp1 sites. This mutation essentially abolished basal promoter activity, although vitD3 was still able to transactivate the -28 HIV-luc construct (Fig. 2), showing that Sp-1 sites are not required for VDR-dependent HIV-1 LTR stimulation. In addition, VDR expression did not affect activity of the plasmid backbone, showing that the effect of vitD3 is mediated by this minimal HIV-1 LTR fragment.

The VP Tat is critical for HIV transcriptional activation, and this effect depends on its binding to the TAR. We transfected HeLa cells with a mutated LTR reporter lacking the TAR element $(-453 \Delta \mathrm{TAR})$, and analyzed the putative effect of VDR on activation of this construct. Figure 2 also shows that although the basal activity was reduced significantly, vitD3-induced transactivation of this construct was similar to that obtained with the wild-type promoter, showing that such effect appears to be independent of the TAR element. The finding that this construct, as well as the -28 HIV-luc construct, are responsive to vitD3 treatment, suggests that the -28 to $30 \mathrm{bp}$ LTR region is sufficient to mediate the receptor effects.

Since VPs appear to cooperate with cellular transcription factors to induce HIV-1 transcription, we also examined whether a functional interaction between Tat and VDR to stimulate LTR activity occurred. For this purpose, a native form of Tat was cotransfected with VDR and the -28 HIV-luc promoter construct harboring the TAR element, and activity was measured in the absence and presence of $100 \mathrm{nM}$ vitD3 (Fig. 3A). Expression of Tat caused a strong stimulation of reporter activity, and interestingly, in the presence of the VP the LTR was activated by vitD3 even in the absence of transfected VDR, showing that Tat was able 


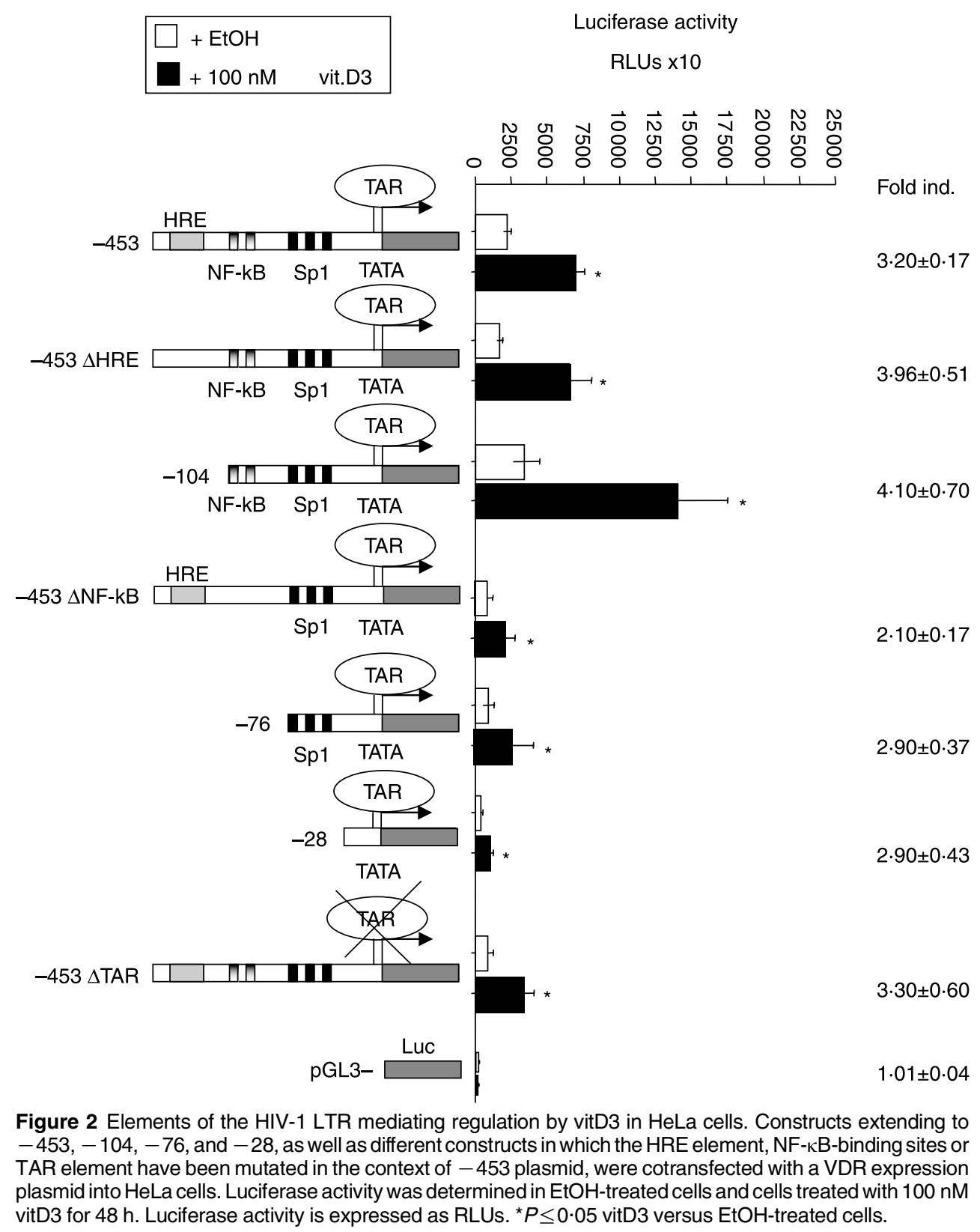

to sensitize the cells allowing a ligand-dependent response through the endogenous receptor. The unliganded receptor was able to synergistically enhance activation by Tat, although in the presence of vitD3 further transactivation was not found indicating saturation of the system. The synergistic effect between the unoccupied receptor and Tat was also observed with the -28 HIV-luc LTR reporter construct. However, the hormone increased the cooperative activation of this minimal reporter construct by these two proteins (Fig. 3B). In addition, the cooperation of VDR and
Tat to activate transcription of this minimal reporter construct was not restricted to HeLa cells, since it was also observed in U937 cells, which, as indicated, could be a natural target for HIV infection (Fig. 3B).

\section{Influence of coactivators on HIV-1 LTR stimulation by VDR}

To assess a possible role of nuclear receptor coactivators in regulation of $H I V$ gene expression by VDR, we cotransfected the HIV-1 LTR luciferase reporter, and 
A
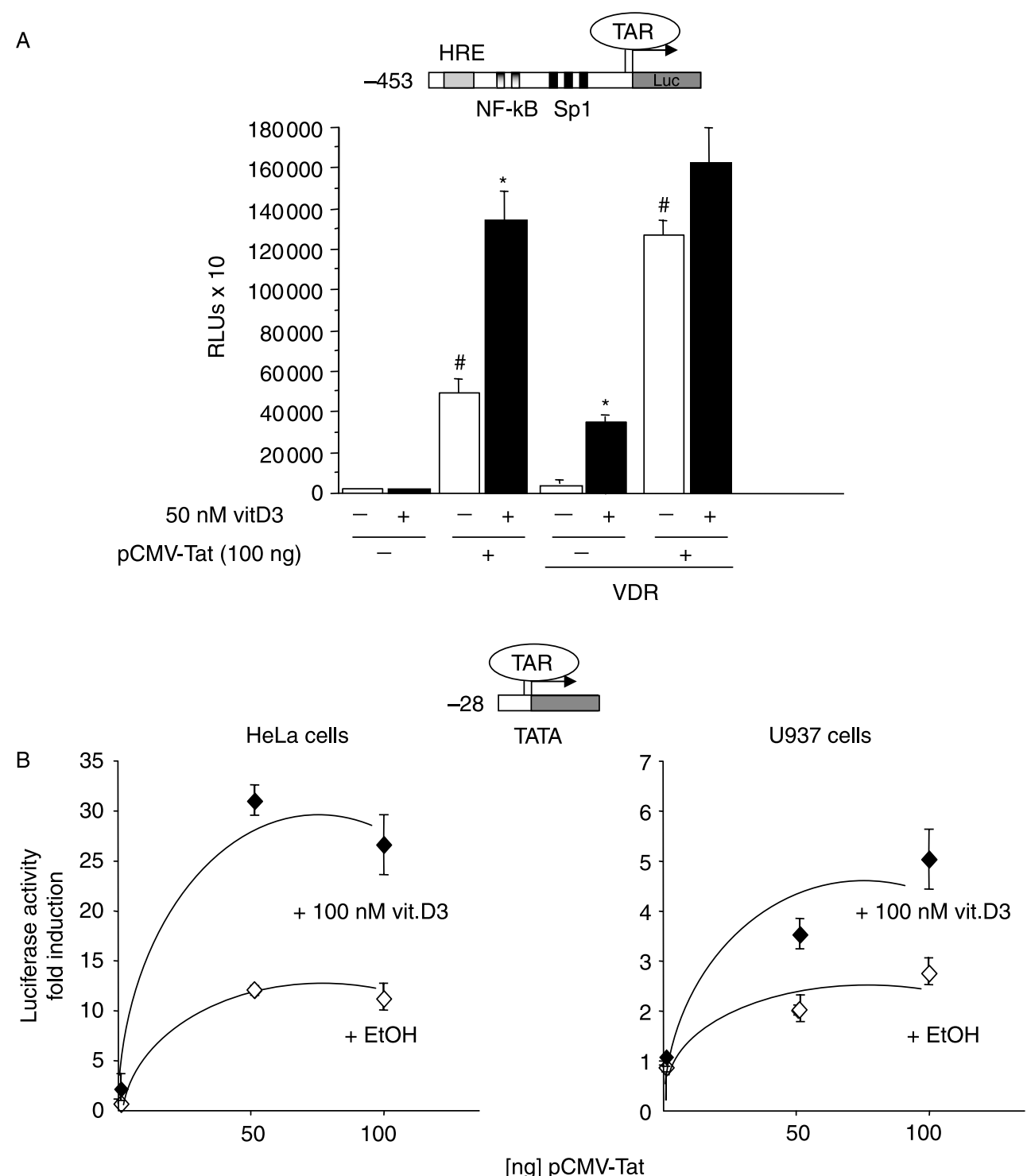

Figure 3 Synergism of Tat with VDR to stimulate the HIV-1 LTR. (A) HeLa cells were transfected with the $-453 \mathrm{HIV}$-Luc reporter in the absence and presence of VDR and/or $100 \mathrm{ng}$ of an expression vector encoding the viral activator Tat (pCMV-Tat). Reporter activity was determined after $48 \mathrm{~h}$ in EtOH-treated cells and cells treated with $50 \mathrm{nM}$ vitD3. ${ }^{*} P \leq 0.05$ vitD3 versus EtOH-treated cells; ${ }^{\#} P \leq 0.05$ versus VDRtransfected cells in the absence of vitD3. (B) HeLa and U937 cells were transiently cotransfected with the -28 HIV LTR reporter and VDR alone or in combination with 50 and $100 \mathrm{ng}$ pCMV-Tat. Luciferase activity was determined in cells incubated with or without $100 \mathrm{nM}$ vitD3 for $48 \mathrm{~h}$. Luciferase activity is expressed as fold induction over the values obtained in the absence of VDR.

the receptor expression plasmid, with expression vectors for different known coactivators for VDR, such as (SRC-1), CREB-binding protein $(\mathrm{CBP} / \mathrm{p} 300)$ or vitamin D-interacting protein 205 (DRIP 205). In all the cases studied, the presence of the coactivator increased VDRinduced HIV-1 LTR transactivation in the absence of ligand (around 2.5-fold). In addition, such a cooperative effect was stronger in the presence of vitD3 (Fig. 4A). Interestingly, the synergistic effect between VDR and either SRC-1 or CBP/p300 was only observed on the complete HIV-1 LTR reporter construct. On several truncated forms of the HIV-LTR, such as $-104,-77$, $\Delta \mathrm{HRE}$ or $\Delta \mathrm{NF}-\kappa \mathrm{B}, \mathrm{VDR}$ was not able to cooperate with the coactivators (data not shown), although it was still able to promote a very significant LTR transactivation in a liganddependent manner (see Fig. 2).

VDR binds DNA preferentially as a heterodimer with the RXR, and we have recently demonstrated that the 

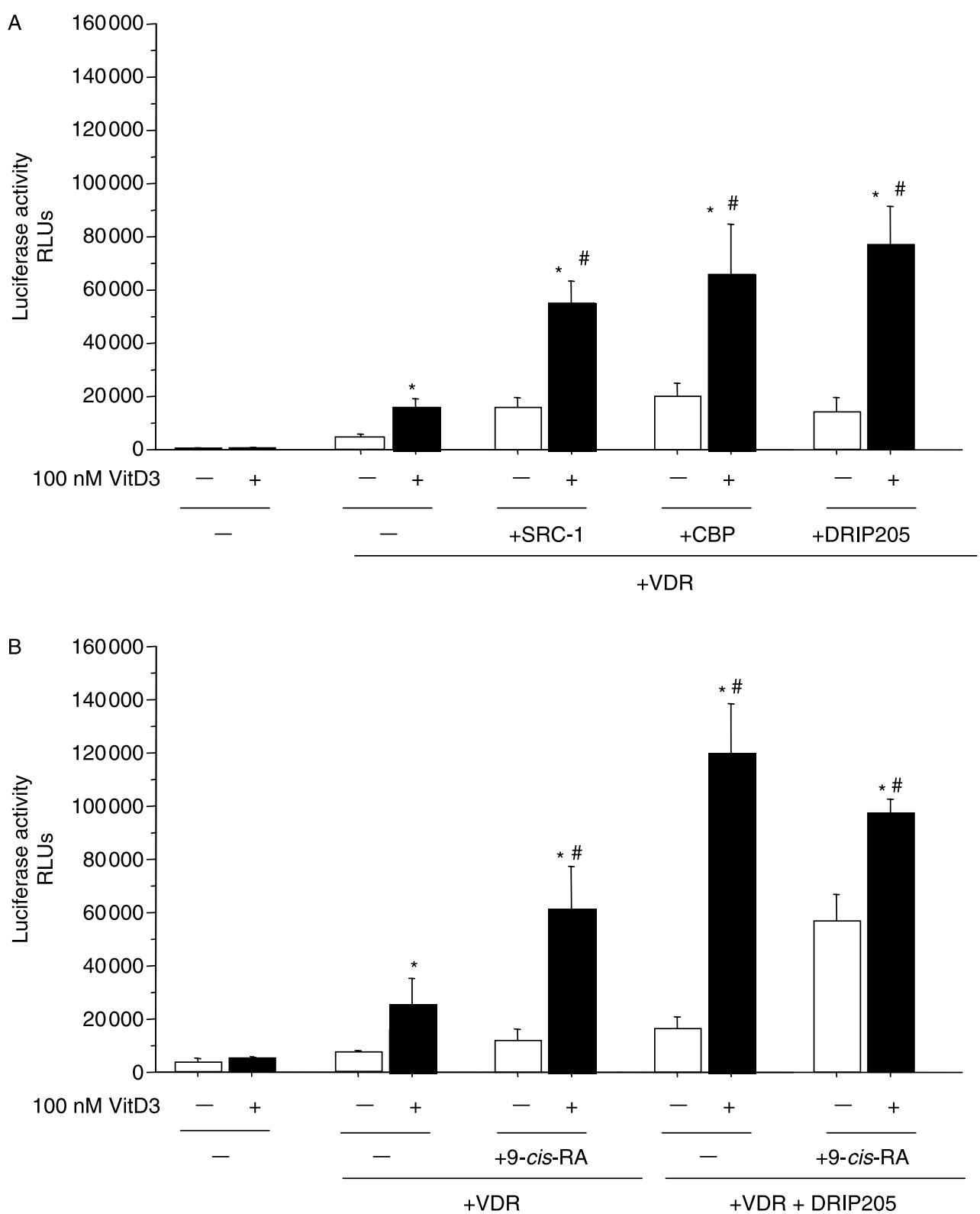

Figure 4 Influence of nuclear receptor coactivators on the HIV-1 response to vitD3. (A) HeLa cells were cotransfected with -453 HIVLuc and VDR expression plasmid alone or in combination with an expression vector for the coactivators SRC-1, CBP/p300, or DRIP205. Luciferase activity was determined in EtOHtreated cells and in cells treated for $48 \mathrm{~h}$ with $100 \mathrm{nM}$ vitD3. (B). VDR acts as a heterodimer with RXR in HIV-1 LTR stimulation. HeLa cells were transfected with -453 HIVLuc and VDR expression plasmid alone or in combination with an expression vector for the coactivator DRIP205. Luciferase activity was determined in $\mathrm{EtOH}$-trated cells and cells treated for $48 \mathrm{~h}$ with $100 \mathrm{nM}$ vitD3 and $1 \mu \mathrm{M} 9$-cis alone or in combination. ${ }^{*} P \leq 0.05$ versus EtOH-treated cells. ${ }^{\#} P \leq 0.05$ versus VDR-transfected cells in the presence of vitD3.

VDR/RXR heterodimer is able to recruit coactivators in response to both vitamin D and the RXR ligand 9-cisRA, and that both ligands can cooperate to stimulate transcription (Sánchez-Martínez et al. 2006). In fact, Fig. 4B shows that 9-cis-RA $(1 \mu \mathrm{M})$ was also able to promote transactivation of the HIV-1 LTR in a synergistic manner with vitD3. Furthermore, 9-cis-RA alone was also able to trigger a cooperative effect between unliganded VDR and DRIP-205 coactivator (Fig. 4B). The presence of vitD3 in the last scenario squelched such cooperative behavior (Fig. 4B). All these data together suggest a role for the VDR/RXR 
heterodimer and its respective ligands in the response of the HIV-1 LTR to vitD3.

\section{Transactivation of the HIV-1 LTR by VDR mutants}

An autonomous AF-2 domain, which is located at the C-terminal helix 12 of the ligand-binding domain, together with residues in helices 3,4 , and 5 form a hydrophobic groove that accommodates the coactivators (Gronemeyer et al. 2004). Furthermore, a conserved glutamic acid in helix 12 (E420) and an invariable lysine (K246) in helix 3 of VDR contact directly with the coactivators and form a charge clamp that stabilizes coactivator binding (Vanhooke et al. 2004). Accordingly, mutations in these residues render a VDR unable to mediate vitamin D-dependent transactivation (Jiménez-Lara \& Aranda 1999a, Sánchez-Martínez et al. 2006). Since the obtained results indicated participation of coactivator molecules in the activation mechanism, we analyzed whether the VDR AF-2 domain plays a role in HIV-1 LTR-induced activation by vitD3. To this end, HeLa cells were cotransfected with $-453 \mathrm{HIV}$-luc and expression vectors for a truncated VDR lacking AF-2 domain, as well as the VDR mutants E420Q and K246A. Figure 5A shows that, surprisingly, these mutations did not eliminate vitD3mediated HIV-1 LTR transactivation. Paradoxically, in some experiments, HIV-1 LTR-induced transcription by these AF-2 VDR mutants seemed to be even higher than that caused by wild-type VDR (around fivefold for K246A and E420Q mutants, Fig. 5A). Western blot analysis of whole HeLa cell lysates revealed nearly equivalent expression of the VDR mutants examined in this assay (data not shown).

Gel retardation assays were performed to confirm that the AF-2 mutants that stimulate HIV-1 LTR promoter activity are indeed unable to recruit coactivators. Whereas, SRC-1 was recruited to the DNA bound VDR/RXR heterodimer in a vitD3-dependent manner, neither the receptor lacking the AF-2 domain nor the E420Q or K246A mutant was able to bind SRC-1 (Fig. 5C). As shown in Fig. 5D, GST pull-down experiments confirmed that the $\triangle \mathrm{AF}-2$ mutant was not able to recruit SRC-1 (lanes 5-8), and that both the E420Q and K246A VDR mutants showed a strongly reduced ability to bind the coactivator (Fig. 5D, lanes 9-16). Thus, surprisingly, VDR mutants that are unable to bind to coactivators are able to strongly induce HIV-1 LTR transactivation.

To investigate whether VDR binding to DNA is necessary for HIV-1 LTR induction, we took advantage of several mutations that affect the DBD. A truncated receptor lacking $111 \mathrm{~N}$-terminal aminoacids, i.e. the $\mathrm{DBD}$ and the $\mathrm{A} / \mathrm{B}$ region that in VDR is only composed of a few residues (Jiménez-Lara \& Aranda 1999b), was not able to promote HIV-1 LTR transactivation in the presence of vitD3 (Fig. 5B). Thus, we further evaluated whether VDR binding to a consensus VDRE was essential for vitD3-mediated LTR transactivation. Consequently, we performed site-directed mutagenesis to create three different DBD mutants affecting the first zinc finger: C24G, K45E, and the double mutant C24G/ K45E. Figure 5B shows that, surprisingly, these three VDR mutants were still able to transactivate the HIV-1 LTR in a hormone-dependent manner with a similar potency to the wild-type VDR.

Gel retardation experiments testing the ability of those mutants to bind DNA and to coactivators showed that these three DBD mutants had a different behavior. While the C24G mutant was still able to bind to a consensus VDRE, K45E, and the double mutant were not (Fig. 5C), although all of them showed a strong ligand-dependent HIV-1 LTR transactivation. On the other hand, in vitro GST pull-down assays confirmed such differences among the different DBD-mutants. C24G was similar to wild-type VDR, and was still able to recruit the coactivator SRC-1 (Fig. 5D), confirming the results obtained in the gel retardation assays (Fig. 5C). The K45E mutant that did not bind DNA (Fig. 5C) was still able to recruit SRC-1, although to a lesser extent than wild-type VDR or the C24G mutant (Fig. 5D). Unexpectedly, the double mutant (C24G/K45E) not only did not bind the VDRE, but also was unable to recruit the coactivator (Fig. 5D). In addition to that, neither the DBD mutants nor the AF-2-mutants were able to synergize with either SRC-1 or CBP coactivators (data not shown). These data suggest that although an intact DBD is not essential for VDR-mediated transactivation of the HIV-1 LTR, this domain may have a role on coactivators recruitment to the LTR. Tethering of a DBD defective VDR to the promoter may happen through interaction with other DNA-binding transcription factors.

In order to confirm that these untypical results regarding transactivation of the HIV-1 LTR by the different VDR mutants used in this analysis are actually HIV-1 LTR promoter specific effects, we compared the ability of wild-type VDR and its different mutants to transactivate a classical VDRE promoter construct $(4 \times$ VDRE-luc). Figure 5E shows that, as expected, the AF-2related mutants $(\triangle \mathrm{AF}-2, \mathrm{~K} 246 \mathrm{~A}$, and $\mathrm{E} 420 \mathrm{Q})$ were not able to activate such promoter construct. In addition, wild-type VDR and the C24G mutant, whose behavior seemed to be similar to wild-type VDR in different aspects (Fig. 5C and D), but not the DBD mutants K45E and $\mathrm{C} 24 \mathrm{G} / \mathrm{K} 45 \mathrm{E}$ were able to transactivate this reporter construct (Fig. 5F). These results are in accordance with a requirement for canonical conditions to activate through a VDRE element, and support the idea that the VDR DBD and AF-2 domains are essential to transactivate in such scenario, but not for VDR-dependent stimulation of the HIV-1 LTR. 

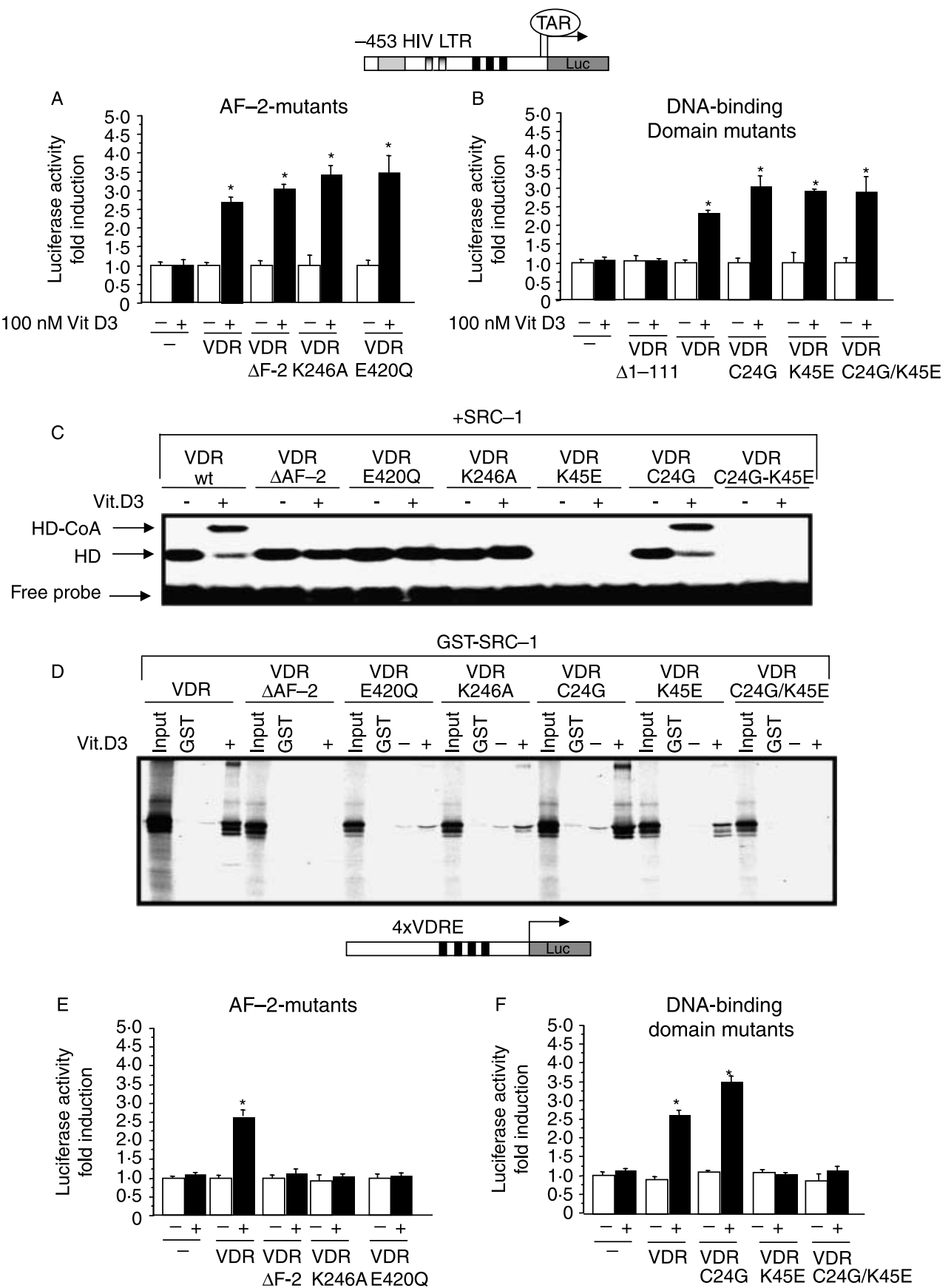

Figure 5 Influence of several VDR mutants on HIV-1 promoter activity. HeLa cells were transfected with $5 \mu \mathrm{g}$ of either $-453 \mathrm{HIVLuc}$ (A and $\mathrm{B}$ ) or $4 \times$ VDRE-TKLuc (E and F) reporter plasmids in combination with an empty expression vector $(-)$, or expression vectors for wt VDR, or for the VDR mutants $\triangle A F-2, K 246 A$, E420Q, $\Delta 1-111, C 24 G, K 45 E$ and C24G/K45E. Luciferase activity was determined in EtOHtreated cells and in cells treated for $48 \mathrm{~h}$ with $100 \mathrm{nM}$ vitamin D3 (vitD3), and is expressed as fold induction over EtOH-treated cells transfected with an empty expression vector. ${ }^{*} P \leq 0.05$ versus EtOH-treated cells. (C) Analysis of DNA binding by VDR mutants. Gel retardation assays were performed with $2.5 \mu \mathrm{l}$ of each in vitro translated RXR and VDR, or VDR-truncated forms, in combination with recombinant SRC-1 in the presence or absence of a saturating concentration of vitD3 $(1 \mu \mathrm{M})$. HD and HD-CoA are the mobility bands corresponding to the VDR/RXR heterodimer and the SRC-1-VDR/RXR complexes, respectively. (D) In vitro interaction between VDR (and different VDR mutants) with SRC-1 was analyzed by GST pull-down, which was performed with $5 \mu \mathrm{l}$ in vitro translated L[ $\left.{ }^{35} \mathrm{~S}\right]$ methionine-labeled receptors. Where indicated, $1 \mu \mathrm{M}$ vitamin $\mathrm{D}$ was included in the binding reaction. The bound proteins were analyzed by SDS-PAGE and autoradiography. The input lanes represent $10 \%$ of the protein in the binding assay. 
That the K45E receptor mutant that does not stimulate a consensus VDRE is able to activate not only the complete LTR, but also the different truncated and mutated HIV-1 LTR reporters is shown in Fig. 6A. This mutant was as potent as the wild-type VDR to transactivate HIV-1 constructs extending to -104 and $-76 \mathrm{bp}$, as well as the HRE, NF- $\kappa \mathrm{B}$ and TAR mutants in the context of -453 HIV-luc. In addition, the influence of the DBD and the AF-2 VDR mutants on vitD3-dependent activation of the -104 HIV-luc construct was also examined. As illustrated in Fig. 6B, the different mutants were able to increase reporter activity in a ligand-dependent manner, showing that the VDR AF-2 and DBD domains are also dispensable for transactivation of this shorter LTR construct. Furthermore, the activity of the minimal reporter construct extending only to $-28 \mathrm{bp}$ was also stimulated by these mutants in a ligand-dependent manner (Fig. 6B), demonstrating again that proximal promoter sequences are sufficient to mediate induction of LTR transcription by vitD3.
To analyze whether mutations in the VDR DBD could abolish binding to a consensus VDRE without affecting binding to the HIV-1 promoter, additional gel retardation assays were performed with an oligonucleotide spanning the -28 to $+30 \mathrm{bp}$ LTR fragment. As shown in Fig. 7, wild-type VDR bound this sequence as a heterodimer with RXR both in the absence and presence of vitD3, whereas no monomeric or homodimeric VDR binding to this LTR region was observed. In contrast, neither VDR K45E nor C24G/K45E were able to bind to this element.

The finding that VDR DBD mutants cannot bind the LTR but enhance its activity suggests that transactivation by these receptors is mediated by interaction with other factors. To analyze whether these mutants could still cooperate with Tat, their influence on stimulation of -453 HIV-luc was also assessed (Fig. 8). In cells transfected with a small amount of Tat vector alone $(10 \mathrm{ng})$, there was little stimulation of reporter activity and again a vitD3-
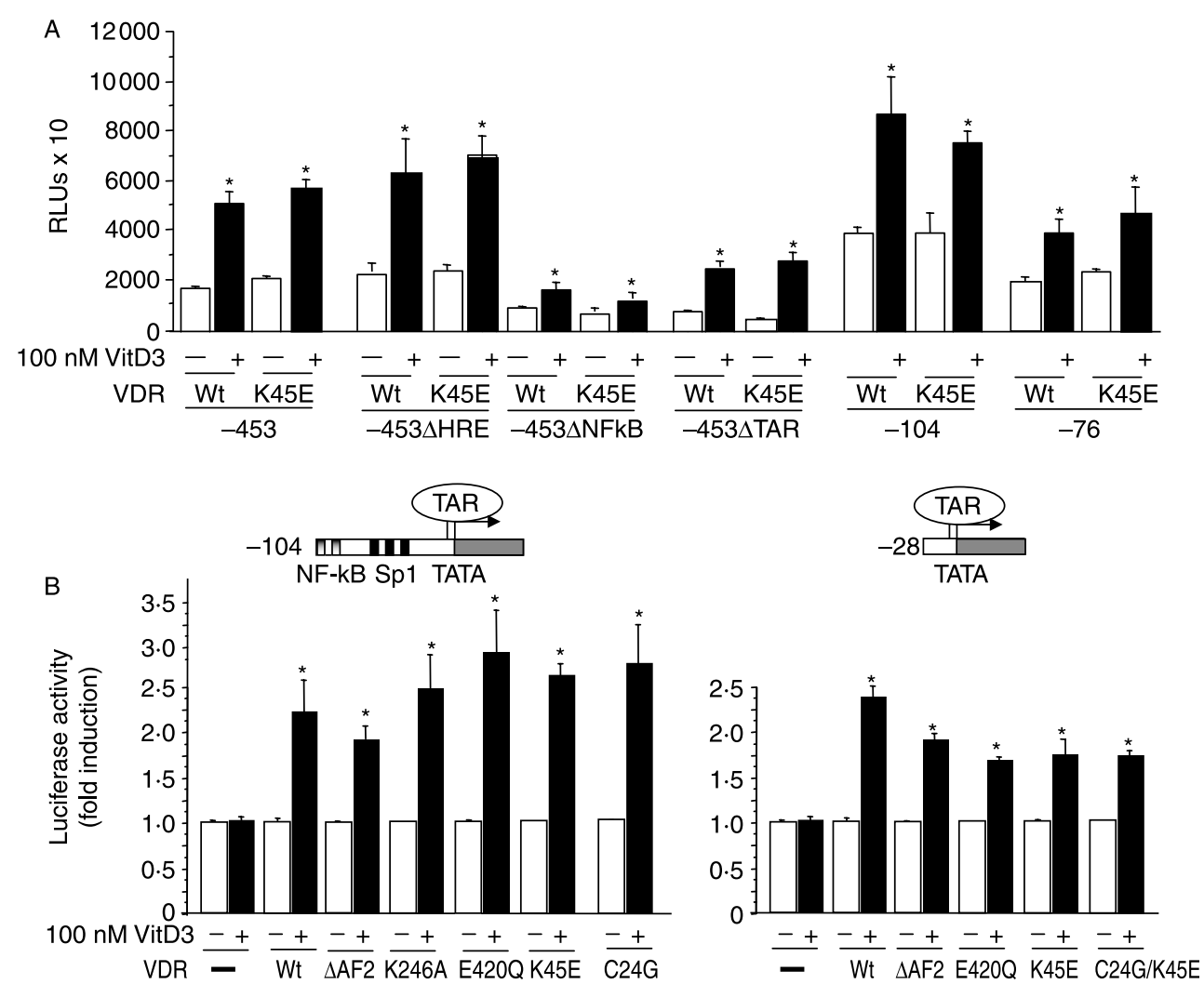

Figure 6 Stimulation of several HIV-1 LTR constructs by VDR mutants. (A) HIV-1 constructs extending to $-453,-104$, and -76 , as well as constructs in which the HRE, NF- $\kappa B$, or TAR elements have been mutated in the context of -453 plasmid, were cotransfected with either wild-type VDR (Wt) or the VDR DBD mutant K45E into HeLa cells. Luciferase activity was determined in EtOH-treated cells and in cells treated with $100 \mathrm{nM}$ vitD3 for $48 \mathrm{~h}$ and is expressed as RLUs. ${ }^{*} P \leq 0.05$ vitD3 versus EtOH-treated cells. (B) The HIV-1 LTR plasmids extending to nucleotides -104 and -28 were cotransfected with either VDR wild-type or the VDR mutants indicated, and reporter activity determined as in (A). Results are expressed as fold induction of vitD3 over EtOH-treated cells for each receptor. ${ }^{\star} P \leq 0.05$ versus EtOH-treated cells. 


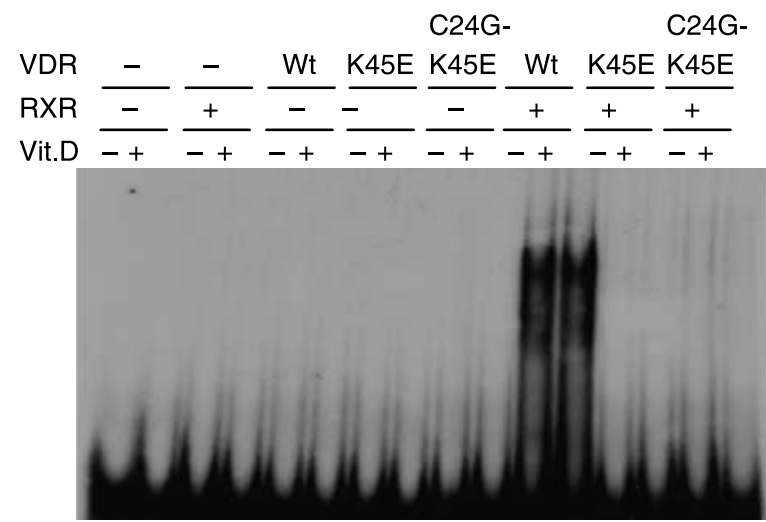

$\begin{array}{llllllllllllllll}1 & 2 & 3 & 4 & 5 & 6 & 7 & 8 & 9 & 10 & 11 & 12 & 13 & 14 & 15 & 16\end{array}$

Figure 7 Binding of VDR mutants to proximal LTR sequences. Gel retardation assays were performed with a labeled oligo nucleotide encompassing the -28 to +30 HIV -1 LTR region. This LTR fragment was incubated with wild-type VDR and the DBD mutants K45E and C24G/K45E in the presence and absence of $\mathrm{RXR}$. When indicated, $1 \mu \mathrm{M}$ vitD3 was present in the binding assay.

dependent response in the absence of transfected VDR was observed. In addition, whereas the wild-type receptor in the absence of ligand was able to cooperate with Tat and did not show a further response to vitD3, the unoccupied VDR K45E and $\mathrm{K} 45 \mathrm{E} / \mathrm{C} 24 \mathrm{G}$ did not cooperate with the VP, although they showed a normal vitD3-dependent response in the absence of Tat.

\section{Discussion}

Our previous findings showed the participation of nuclear receptors, transcription factors and coactivators in the stimulation of $H I V$ gene expression by RA in neuronal cells (Recio et al. 2000), demonstrating that both host and VPs cooperate to induce RA-mediated transcription of HIV. In addition, it has been also suggested a role for the T3 in HIV-1 LTR regulation, revealing the existence of binding sites for the T3 receptor (T3R) in different regions of the LTR sequence (Sawaya et al. 1996, Xu et al. 1996, Recio et al. 2000, Hsia \& Shi 2002). In this sense, previous studies have revealed that different hormones, such as T3, may have a role in AIDS development (LoPresti et al. 1989), and a therapeutic use of retinoic antagonists has been already proposed to repress viral replication by inhibiting retinoid-dependent transcription (Lee et al. 1994, 1996, Hanley et al. 2004).

In this work, we have analyzed the activation of the HIV-1 LTR by another nuclear receptor, VDR. Our results clearly show that VDR is also a potent HIV-1 LTR transactivator in a vitD3-dependent manner in HeLa cells. However, in order to give a more physiological significance to HIV-1 LTR transactivation by VDR, and to exclude a cell-type specific effect, we also analyzed the role of VDR on the LTR in U937 cells, as a model of mononuclear cells, which are a HIV-1 virus target. Our data show VDR-dependent activation of the HIV-1 LTR in this cell type, supporting a possible role for this

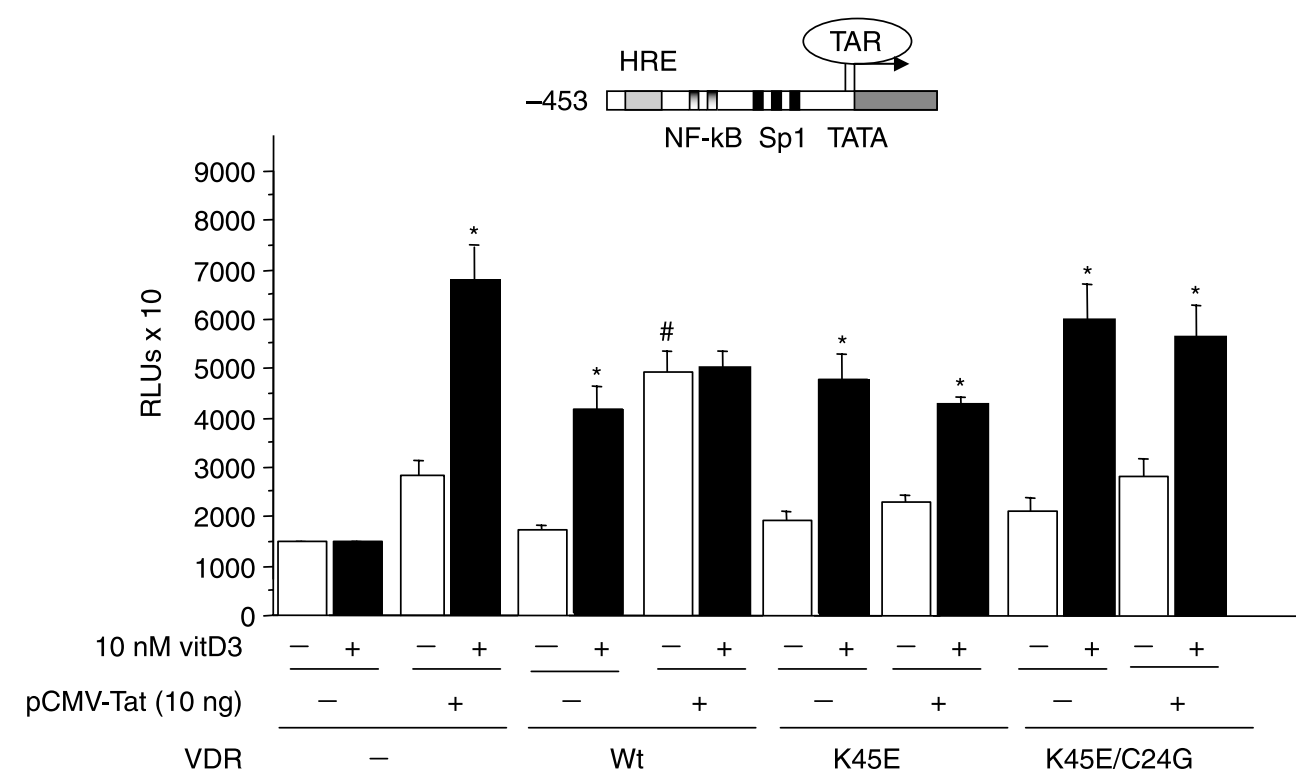

Figure 8 The VDR mutants in the DNA-binding domain do not cooperate with Tat. HeLa cells were transfected with the $-453 \mathrm{HIV}$-luc promoter construct, $10 \mathrm{ng}$ pCMV-Tat and expression vectors for wildtype VDR and the DBD mutants K45E and C24G/K45E. Luciferase activity was determined after $48 \mathrm{~h}$ incubation with EtOH or vitD3 and is expressed as RLUs. ${ }^{\star} P \leq 0.05$ vitD3 versus $\mathrm{EtOH}$-treated cells. 
receptor in HIV-LTR-mediated transactivation and therefore on the progress of AIDS.

New receptor chemical modulators are valuable tools for studying the molecular mechanisms of VDR signaling and could also be good candidates to modulate HIV-1 LTR activity and therefore viral transcription and replication. Some of these compounds show a clear agonistic activity and are at least as strong as the natural ligand. This is the case for ZK16422 (Castillo et al. 2006) that also stimulated the LTR. In contrast, compounds such as ZK159222, which binds VDR with high affinity but only shows a residual agonistic activity at high concentrations, can inhibit vitD3-dependent transactivation (Castillo et al. 2006), and might therefore be useful to repress viral transcription in response to the endogenous ligand.

Trying to unmask the regulatory regions involved in HIV-1 LTR transactivation by VDR, we used a series of deletion mutants. An HRE that can bind multiple nuclear receptors, including VDR (Ladias 1994) was expected to be responsible for vitD3-dependent stimulation. However, our data reveal that when the HRE was deleted a full transactivation of the LTR was still observed. We have previously observed a similar result for RA-mediated stimulation of HIV-1 LTR in neuronal cells (Recio et al. 2000). Surprisingly, the HRE seemed to be necessary for cooperation between VDR and the SRC-1 coactivator. On the other hand, a truncated HIV LTR form, in which sequences from -453 to $-104 \mathrm{bp}$ were deleted, showed increased transcription by the unoccupied VDR, without affecting vitD3-mediated LTR activation, and suggesting that a putative repressive element could be located within this region. All these results together suggest that other downstream-located sequences (different from the HRE) are involved in ligand-dependent stimulation of $H I V$ gene expression.

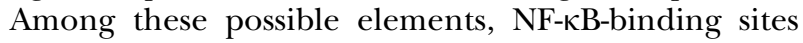
were good candidates to be involved in VDR-dependent transcription of HIV-1 LTR. However, our data do not demonstrate an important role for these sites. In contrast, NF- $\mathrm{BB}$ sites seemed to be responsible for most basal activity of the LTR in HeLa cells. In a further dissection analysis of HIV-1 LTR, we also examined a role for the binding sites for the transcription factor Sp1, which seems to play (together with NF- $\kappa$ B transcription factors), a crucial role in $H I V-1$ gene expression (Perkins et al. 1993, Jones \& Peterlin 1994). We have previously shown that RA was not able to promote activation of a minimal LTR construct lacking the Sp1 sites (-28 HIV-luc; Recio et al. 2000). In addition, Sp1 appears to mediate HIV-1 LTR induction by other nuclear receptor (ER $\alpha$; Katagiri et al. 2006), and binding of TR to both NF- $\kappa \mathrm{B}$ and Sp1 sites that appear to be implicated in regulation of HIV-1 LTR activity by this receptor has been reported (Desai-Yajnik \& Samuels 1993). However, our data also exclude a major role for the Sp1 motifs in VDR-dependent HIV-1 stimulation because the -28 HIV-luc minimal construct was still able to respond to vitD3.

Previous findings from our laboratory documented the existence of unrecognized nuclear receptor-binding sites in HIV-1 core promoter sequences located both upstream and downstream of the TATA box. Sequences contained between nucleotides -35 and +89 of the HIV-1 LTR can bind VDR-RXR heterodimers (Recio et al. 2000). In contrast with NF- $\mathrm{B}$ or Sp1 LTR motifs, which are rather selective for TR-RXR, these proximal elements can also bind RAR-RXR and VDR-RXR (Recio et al. 2000). In this study, we have shown that the HIV-1 LTR region comprised between nucleotides -28 and +30 bind VDR-RXR heterodimers, whereas neither monomers nor homodimers show high affinity binding to this element. The existence of various nuclear receptor-binding sites, both in the modulatory and in the proximal promoter region, may point at the importance of signaling by these transcription factors in HIV transactivation, which may ensure transcriptional regulation of the virus by different mechanisms even after an eventual mutation of the canonical receptor-binding site (HRE).

The synergism obtained between VDR and the viral Tat protein, both in HeLa and U937 cells, constitutes another example of the cooperation between host and VPs to induce HIV-1 transcription. A similar cooperative effect between Tat and RAR has been previously described by us (Recio et al. 2000). Tat is a potent transactivator of HIV-LTR gene expression and replication, which basically acts through a direct interaction with a RNA sequence, called TAR element, located between oligonucleotides +4 and +44 , although several studies suggest that Tat is also able to activate gene expression in the absence of TAR (Taylor et al. 1992, Dal Monte et al. 1997, Yang et al. 1997; and Nevado et al. unpublished observations). Although the TAR element is not required for VDR-mediated HIV-LTR gene expression, cooperation of Tat with the receptor could facilitate targeting of coactivators and the transcriptional machinery to the promoter and the synergistic activation. Tat seems to be able to interact in vitro with many proteins, including basic transcriptional machinery components (Jones \& Peterlin 1994), and other nuclear receptors such as TR (Desai-Yajnik et al. 1995). Therefore, a protein-protein interaction of Tat with VDR could be involved in the cooperation observed.

Our findings also reveal that VDR domains essential for vitD3-mediated transactivation of a VDREcontaining promoter, do not seem to be required for HIV-LTR transactivation by VDR in HeLa cells. Thus, point mutations in the DBD that abolish receptor binding to a consensus VDRE as well as VDRE-mediated transcription do not affect LTR activation by vitD3. In 
contrast, deletion of the DBD abolishes induction, showing the importance of this domain for activation. Surprisingly, our data show that DBD mutations can affect not only DNA binding but also association with SRC-1, suggesting an additional role for this domain in VDR-mediated transcription through recruitment coactivators of the p160 family. On the other hand, VDR mutants lacking the AF-2 domain or point mutations affecting critical residues in helices 3 and 12 that are inactive to stimulate transcription through a classical VDRE, are still able to confer vitD3-dependent HIV-1 LTR induction. All these data together seem to point, among other mechanisms, at putative protein-protein interactions to drive VDR-mediated LTR transactivation in a ligand-dependent manner. Interestingly, the DBD mutants that can mediate vitD3-dependent HIV-1 LTR transcription are unable to cooperate with Tat.

Our results show that several nuclear receptor coactivators cause a significant increase in the induction of LTR transcription by both the unoccupied and ligand-bound receptor. Some of these coactivators, such as the p160 protein SRC-1 or CBP possess histone acetyltransferase activity (HAT) that cause chromatin decompactation, thus facilitating transcription (Aranda \& Pascual 2001, Gronemeyer et al. 2004, Perissi \& Rosenfeld 2005), while DRIP205, a component of the mediator complex, functions to recruit the RNApol II holoenzyme to the target promoter (Rachez et al. 1998, 1999). Although the AF-2 VDR mutants are able to stimulate the LTR, they have lost the ability to synergize with SRC-1 or CBP. The finding that the VDR AF-2 domain is not required for vitD3-mediated transactivation of the LTR, suggest that recruitment by other promoter-bound transcription factors could be involved in the stimulatory effect of the coactivators. In agreement with this hypothesis, CPB/p300 also acts as a coactivator for NF- $\kappa \mathrm{B}$ (Perkins et al. 1997) and Tat (Hottiger \& Nabel 1998, 2000). The interaction of Tat with HAT complexes and their strong relevance in HIV1 LTR activation has been established (Benkirane $e t$ al. 1998, Marzio et al. 1998, Rachez et al. 1998, Ott et al. 1999, Dorr et al. 2002, Kino et al. 2002, Mujtaba et al. 2002, Mahmoudi et al. 2006). In addition, Tat itself is subject to modification by acetyltransferases that regulate its activity (Ott et al. 1999, Kino et al. 2002, Mahmoudi et al. 2006). On the other hand, it has been described that p160 coactivators function as coactivators of the HIV-1 LTR. The p160 proteins appear to be tethered to the LTR via association with NF- $\kappa \mathrm{B}$, allowing full activation of this promoter by Tat (Kino et al. 2002). Whether or not the different receptor mutants can be recruited in vivo to the LTR either directly or through protein-protein interactions with other factors remains to be analyzed in future studies.

In addition to Tat, other VPs such as VPR are thought to influence not only viral replication but also numerous host cell functions (Kino \& Pavlakis 2004). Transcription factors such as Sp1 or the glucocorticoid receptor (GR) and coactivators such as $\mathrm{CBP} / \mathrm{p} 300$ also interact with VPR, which has been shown to act as a coactivator for GR (Kino et al. 1999). Therefore, it is possible that this important HIV-1 regulatory molecule could also have a function on LTR activation by VDR.

In conclusion, our data point to the importance of VDR signaling in HIV transactivation, which can occur through 'classical' and 'non-classical' mechanisms. All together seem to support the participation of receptors and their agonist ligands, transcription factors, cellular coactivators, and VPs in the stimulation of HIV gene expression by vitD3, although additional efforts will be necessary to reveal their specific role in such a process. Because the LTR represents the main regulatory region for viral replication, our present findings suggest that the vitamin $\mathrm{D}$ receptor may play a role during the infectious process and in the progress of AIDS in patients.

\section{Acknowledgements}

We are grateful to Drs LR Gaudreau, RM Evans, M Parker, L Freedman, J Alcamí, B Berkhout, and D Barettino for kindly providing plasmids and Dr S Alemany for the U-937 cell line. We also thank Dr Andreas Steinmeyer from Schering AG (Berlin, Germany) for the vitamin D analogs.

\section{Funding}

This work has been supported by the Grant BFU2004 03465. $\mathrm{J} \mathrm{N}$ is a recipient of a Research contract from ISCIII (FIS 99/3077), and A I C was supported by a postdoctoral fellowship of the Ernst Schering Research Foundation. Finally, the authors declare that there is no conflict of interest that would prejudice the impartiality of this scientific work.

\section{References}

Aranda A \& Pascual A 2001 Nuclear hormone receptors and gene expression. Physiological Reviews 81 1269-1304.

Barber Y, Rubio C, Fernandez E, Rubio M \& Fibla J 2001 Host genetic background at CCR5 chemokine receptor and vitamin $\mathrm{D}$ receptor loci and human immunodeficiency virus (HIV) type 1 disease progression among HIV-seropositive injection drug users. Journal of Infectious Disease 184 1279-1288.

Benkirane M, Chun RF, Xiao H, Ogryzko VV, Howard BH, Nakatani Y \& Jeang KT 1998 Activation of integrated provirus requires histone acetyltransferase. p300 and P/CAF are coactivators for HIV-1 Tat. Journal of Biological Chemistry 273 24898-24905.

Castillo AI, Sanchez-Martínez R, Jiménez-Lara A, Steinmeyer A, Zügel U \& Aranda A 2006 Characterization of vitamin D receptor ligando with cell-specific and "dissociated" activity. Molecular Endocrinology 20 3093-3104. 
Chakrabarti D, LaMorte VJ, Nelson MC, Nakajima T, Schulman IG, Juguilon H, Montmini M \& Evans RM 1996 Role of CBP/p300 in nuclear receptor signalling. Nature 383 99-102.

Dal Monte P, Landini MP, Sinclair J, Virelizier JL \& Michelson S 1997 TAR and Spl-independent transactivation of HIV long terminal repeat by the Tat protein in the presence of human cytomegalovirus IE1/IE2. AIDS 11 297-303.

Desai-Yajnik V \& Samuels H 1993 The NF-kappa B and Spl motifs of the HIV-1 long terminal repeat function as novel thyroid hormone response elements. Molecular and Cellular Biology 13 5057-5069.

Desai-Yajnik V, Hadzic E, Modlinger P, Malhotra S, Gechlik G \& Samuels HH 1995 Interactions of thyroid hormone receptor with the human immunodeficiency virus type 1 (HIV-1) long terminal repeat and the HIV-1 Tat transactivator. Journal of Virology 68 5103-5112.

Devary Y, Rosette C, DiDonato JA \& Karin M 1993 NF-kappa B activation by ultraviolet light not dependent on a nuclear signal. Science 261 1442-1445.

Dorr A, Kiermer V, Pedal A, Rackwitz HR, Henklein P, Schubert U, Zhou MM, Verdin E \& Ott M 2002 Transcriptional synergy between Tat and PCAF is dependent on the binding of acetylated Tat to the PCAF bromodomain. EMBO Journal 21 2715-2723.

Gomez-Gonzalo M, Carretero M, Rullas J, Lara-Pezzi E, Aramburu J, Berkhout B, Alcami J \& Lopez-Cabrera M 2001 The hepatitis B virus $\mathrm{X}$ protein induces HIV-1 replication and transcription in synergy with T-cell activation signals: functional roles of NF-kappaB/NF-AT and SP1-binding sites in the HIV-1 long terminal repeat promoter. Journal of Biological Chemistry 276 35435-35443.

Gronemeyer H, Gustafsson JA \& Laudet V 2004 Principles for modulation of the nuclear receptor superfamily. Nature Reviews. Drug Discovery 3 950-964.

Hanley TM, Kiefer HLB, Schnitzler AC, Marcello JE \& Viglianti GA 2004 Retinoid-dependent restriction of human immunodeficiency virus type 1 replication in monocytes/macrophages. Journal of Virology 78 2819-2830.

Henttu PM, Kalkhoven E \& Parker MG 1997 AF-2 activity and recruitment of steroid receptor coactivator 1 to the estrogen receptor depend on a lysine residue conserved in nuclear receptors. Molecular and Cellular Biology 17 1832-1839.

Herdick M, Bury Y, Quack M, Uskokovic MR, Polly P \& Carlberg C 2000 Response element and coactivator-mediated conformational change of the vitamin $\mathrm{D}(3)$ receptor permits sensitive interaction with agonists. Molecular Pharmacology 57 1206-1217.

Hottiger MO \& Nabel GJ 1998 Interaction of human immunodeficiency virus type 1 Tat with the transcriptional coactivators p300 and CREB binding protein. Journal of Virology 72 8252-8256.

Hottiger MO \& Nabel GJ 2000 Viral replication and the coactivators p300 and CBP. Trends in Microbiology 8 560-565.

Hsia SC \& Shi YB 2002 Chromatin disruption and histone acetylation in regulation of the human immunodeficiency virus type 1 long terminal repeat by thyroid hormone receptor. Molecular and Cellular Biology 22 4043-4052.

Jiménez-Lara A \& Aranda A $1999 a$ Lysine 246 of the vitamin D receptor is crucial for ligand-dependent interaction with coactivators and transcriptional activity. Journal of Biological Chemistry 274 13503-13510.

Jiménez-Lara A \& Aranda A 1999 b Vitamin D represses retinoic aciddependent transactivation of the retinoic acid receptor- $\beta 2$ promoter: the AF-2 domain of the vitamin $\mathrm{D}$ receptor is required for transrepression. Endocrinology 140 2898-2907.

Jones KA \& Peterlin BM 1994 Control of RNA initiation and elongation at the HIV-1 promoter. Annual Review of Biochemistry 63 717-743.

Katagiri D, Hayashi H, Victoriano AF, Okamoto T \& Onozaki K 2006 Estrogen stimulates transcription of human immunodeficiency virus type 1 (HIV-1). International Immunopharmacology 6 170-181.
El Kharroubi A, Piras G, Zensen R \& Martin MA 1998 Transcriptional activation of the integrated chromatin-associated human immunodeficiency virus type 1 promoter. Molecular and Cellular Biology 18 2535-2544.

Kino T \& Pavlakis GN 2004 Partner molecules of accessory protein Vpr of the human immunodeficiency virus type 1. DNA and Cell Biology 23 193-205.

Kino T, Gragerov A, Kopp JB, Stauber RH, Pavlakis GN \& Chrousos GP 1999 The HIV-1 virion-associated protein vpr is a coactivator of the human glucocorticoid receptor. Journal of Experimental Medicine 51 62.

Kino T, Slobodskaya O, Pavlakis GN \& Chrousos GP 2002 Nuclear receptor coactivator p160 proteins enhance the HIV-1 long terminal repeat promoter by bridging promoter-bound factors and the Tat-P-TEFb complex. Journal of Biological Chemistry $\mathbf{2 7 7}$ 2396-2405.

Ladias JA 1994 Convergence of multiple nuclear receptor signaling pathways onto the long terminal repeat of human immunodeficiency virus-1. Journal of Biological Chemistry $2695944-5951$.

Lee MO, Hobbs PD, Zhang XK, Dawson MI \& Pfahl M 1994 A synthetic retinoid antagonist inhibits the human immunodeficiency virus type 1 promoter. PNAS 91 5632-5636.

Lee MO, Hobbs PD, Zhang XK, Dawson MI \& Pfahl M 1996 A novel class of retinoid antagonists and their mechanism of action. Journal of Biological Chemistry 271 11897-11903.

LoPresti JS, Fried JC, Spencer CA \& Nicoloff JT 1989 Unique alterations of thyroid hormone indices in the acquired immunodeficiency syndrome (AIDS). Annals of Internal Medicine 110 970-975.

Mahmoudi T, Parra M, Vries RG, Kauder SE, Verrijzer CP, Ott M \& Verdin E 2006 The SWI/SNF chromatin-remodeling complex is a cofactor for Tat transactivation of the HIV promoter. Journal of Biological Chemistry 281 19960-19968.

Mangelsdorf DJ, Thummel C, Beato M, Herrlich P, Schutz G, Umesono K, Blumberg B, Kastner P, Mark M, Chambon P et al. 1995 The nuclear receptor superfamily: the second decade. Cell 83 835-839.

Marzio G, Tyagi M, Gutierrez MI \& Giacca M 1998 HIV-1 tat transactivator recruits p300 and CREB-binding protein histone acetyltransferases to the viral promoter. PNAS 95 13519-13524.

Mujtaba S, He Y, Zeng L, Farooq A, Carlson JE, Ott M, Verdin E \& Zhou MM 2002 Structural basis of lysine-acetylated HIV-1 Tat recognition by PCAF bromodomain. Molecular Cell 9 575-586.

Nieto G, Barber Y, Rubio MC, Rubio M \& Fibla J 2004 Association between AIDS disease progression rates and the Fok-I polymorphism of the VDR gene in a cohort of HIV-1 seropositive patients. Journal of Steroid Biochemistry and Molecular Biology 89/90 199-207.

Ott M, Schnölzer M, Garnica J, Fischle W, Emiliani S, Rackwitz HR \& Verdin E 1999 Acetylation of the HIV-1 Tat protein by p300 is important for its transcriptional activity. Current Biology 9 1489-1492.

Pereira LA, Bentley K, Peeters A, Churchill MJ \& Deacon NJ 2000 A compilation of cellular transcription factor interactions with the HIV-1 LTR promoter. Nucleic Acids Research 28 663-668.

Perissi V \& Rosenfeld MG 2005 Controlling nuclear receptors: the circular logic of cofactor cycles. Nature Reviews. Molecular Cell Biology 6 542-554.

Perkins ND, Edwards N, Duckett C, Agranoff A, Schmid R \& Nabel GJ 1993 A cooperative interaction between NF-Kappa B and Sp1 is required for HIV-1 enhancer activation. EMBO Journal 12 3551-3558.

Perkins ND, Felzein LK, Betts JC, Leung K, Beach DH \& Nabel GJ 1997 Regulation of NF-kappaB by cyclin-dependent kinases associated with the p300 coactivator. Science 275 523-527.

Rachez C, Suldan Z, Ward J, Chang CP, Burakov D, ErdjumentBromage H, Tempst P \& Freedman LP 1998 A novel protein complex that interacts with the vitamin D3 receptor in a liganddependent manner and enhances VDR transactivation in a cell-free system. Genes and Development 12 1787-1800. 
Rachez C, Lemon BD, Suldan Z, Bromleigh V, Gamble M, Naar AM, Erdjument-Bromage H, Tempst P \& Freedman LP 1999 Liganddependent transcription activation by nuclear receptors requires the DRIP complex. Nature 398 824-828.

Recio JA \& Aranda A 1997 Activation of the HIV-1 long terminal repeat by nerve growth factor. Journal of Biological Chemistry 272 26807-26810.

Recio JA, Martinez de la Mata J, Martin-Nieto J \& Aranda A 2000 Retinoic acid stimulates HIV-1 transcription in human neuroblastoma SH-SY5Y cells. FEBS Letter 469 118-122.

Rohr O, Marban C, Aunis D \& Schaeffer E 2003 Regulation of HIV-1 gene transcription: from lymphocytes to microglial cells. Journal of Leukocyte Biology 74 736-749.

Sánchez-Martínez R, Castillo AI, Steinmeyer A \& Aranda A 2006 The retinoid $\mathrm{X}$ receptor ligand restores defective signalling by the vitamin D receptor. EMBO Reports 7 1030-1034.

Sawaya BE, Rohr O, Aunis D \& Schaeffer E 1996 Regulation of human immunodeficiency virus type 1 gene transcription by nuclear receptors in human brain cells. Journal of Biological Chemistry 271 22895-22900.
Taylor JP, Pomerantz R, Bagasra O, Chowdhury M, Rappaport J, Khalili K \& Amini S 1992 TAR-independent transactivation by Tat in cells derived from the CNS: a novel mechanism of $H I V-1$ gene regulation. EMBO Journal 11 3395-3403.

Vanhooke JL, Benning MM, Bauer CB, Pike JW \& DeLuca HF 2004 Molecular structure of the rat vitamin D receptor ligand binding domain complexed with 2-carbon-substituted vitamin D3 hormone analogues and a LXXLL-containing coactivator peptide. Biochemistry 43 4101-4110.

Xu J, Luznik L, Wong-Staal F \& Gill GN 1996 Hormone receptor regulation of the human immunodeficiency virus type 1 and type 2 long terminal repeats. Journal of Biomedical Science 3 323-331.

Yang L, Morris GF, Lockyer JM, Lu M, Wang Z \& Morris CB 1997 Distinct transcriptional pathways of TAR-dependent and TARindependent human immunodeficiency virus type-1 transactivation by Tat. Virology 235 48-64.

Received in final form 5 March 2007

Accepted 25 March 2007

Made available online as an Accepted Preprint 28 March 2007 